\title{
The Impact of Train and Station Types on Perceived Rail Service Quality.
}

\section{Fredrik Monsuur}

School of Civil \& Building Engineering, Loughborough University

Loughborough LE11 3TU, United Kingdom

Tel: +44 7802418 565; Email: F.Monsuur@lboro.ac.uk

Dr Marcus Enoch

School of Civil \& Building Engineering, Loughborough University

Loughborough LE11 3TU, United Kingdom

Tel: +44 1509223 408; Email: M.P.Enoch@lboro.ac.uk

\section{Professor Mohammed Quddus*}

School of Civil \& Building Engineering, Loughborough University

Loughborough LE11 3TU, United Kingdom

Tel: +44 (0) 1509228545; Email: m.a.quddus@lboro.ac.uk

\section{Dr Stuart Meek}

Govia Thameslink Railway Ltd.

London EC3R 8AJ, United Kingdom

Tel: +44 7896556 677; Email: stuart.meek@gtrailway.com

* Corresponding author

Word count: 6,230 words text +2 tables/figures x 250 (each) $=6,730$ words.

TRB paper number: 17-03298

Submission Date: $15^{\text {th }}$ March 2017 


\begin{abstract}
This paper aims to highlight the impact of train and station types in the evaluation of service quality, whilst taking account of a range of relevant trip and socio-demographic factors. It applies a partial constrained proportional odds model (an extension of ordered logit model) to data extracted from the $32^{\text {nd }}$ wave of the National Rail Passenger Survey (NRPS) held in spring 2015, which comprises around 30,000 trip-level observations of passenger satisfaction of rail services across Great Britain.

The results indicate that the impact of train types on service quality is significant. Thus, for type of train services the modelling results indicate that high speed rail, long distance, inter urban rail and especially open access operators are more likely to lead to satisfied customers compared to commuter and rural railway services. For stations, users of the smallest station category are more likely to be satisfied than those of larger category stations, but other station types do not significantly impact satisfaction. Next, delays have a significant negative impact on satisfaction levels. Considering passenger segments, respondents in the oldest age category are more likely to be satisfied compared to respondents in the youngest age category and commuters are less likely to be satisfied compared to respondents on a business or leisure trip. Overall these results show how TOCs (Train Operating Companies) might best focus their efforts on improving passenger satisfaction according to train type, station type, and trip stage and/or user segment.
\end{abstract}




\section{INTRODUCTION}

Delivering a quality service that meets the expectations and needs of its customers is an important commercial aspect of running a railway. This is for three reasons. First, dissatisfied passengers might switch to alternative travel modes if these are available or else decide not to travel at all, whereas satisfied passengers tend to be loyal to the railway mode $(1,2,3$, 4). Second, satisfaction is of importance for railway companies because it is used to monitor and benchmark performance and increasingly such satisfaction measures relate directly to payments made to TOCs (Train Operating Companies) as part of their franchise agreements, e.g. the Thameslink, Great Northern and Southern franchise (5). Third, poor satisfaction might lead to reputational damage for TOCs (6), which may further lead to longer term impacts on both patronage levels and the chances of winning/retaining future franchise competitions. Taken together, underperformance in terms of passenger satisfaction can significantly impact on the profitability of a TOC, as margins are already small - with a maximum of around 5\% (7). However, despite widespread recognition of the importance of passenger satisfaction across the UK rail sector, in practice improving the situation has proven difficult to achieve. For instance, the average level of passenger satisfaction in 2015 was only 80\% - that is 5\% lower level than in 2010 (8).

In attempting to explain this, perhaps the dominant factor is that much of the UK railway system is now operating close to (or in some cases above) capacity for much of the time, rail demand having more than doubled to almost 1.7 billion journeys per annum since the process of privatisation began in 1994 (9). Therefore, large investment schemes are currently being conducted to improve and extend the railway network. To make sure that these investments meet the needs of passengers it is important to understand their evaluation of service quality.

Accordingly, the aim of this paper is to highlight the impact of train and station types in the evaluation of service quality, whilst taking account of a range of relevant trip and socio-demographic factors. This will provide useful knowlegde into which elements of the railway service are more likely to lead to satisfied passengers and which elements are not, and could therefore be improved. This paper proposes the use of a partially constrained proportional odds model to estimate these effects. The results should help policy makers and TOC managers understanding the needs of customers in the UK railway.

\section{LITERATURE REVIEW}

In the marketing literature it is argued that service quality from a passenger's point of view should form a key component in the evaluation of any transport system. This is because passengers are the users of the system, and hence they are best placed to judge whether the service meets their expectations $(10,11)$. Service quality not only matters to passengers, but also to operators and politicians, because passenger perceptions of service quality could directly translate towards the success of a transit system in terms of demand and revenue $(1,2,3)$.

However, service quality is not very straightforward to measure, which perhaps explains why it has only been actively considered relatively recently. Thus, whereas increasing focus on improving cost efficiency in public transport gathered momentum from the 1980s onwards, typically via the introduction of competitive tendering or economic deregulation (12), the inclusion of service quality measures in franchise contracts gained ground around the 2000s in Europe, especially with the introduction of the EU standard on public transport service quality EN13816 (13). Subsequently, service quality measures in public transport gained significant attention in the literature and started to influence performance incentives in public transport contracts $(5,12,14)$.

First of all, there is a discussion on the definition of service quality in the marketing literature. Service quality is hard to define and the literature often uses it interchangeably with 
satisfaction. However, they are not the same. Service quality is described as an attitude, a long run evaluation of the service provided to the customer, whereas satisfaction can be seen as a measure based on the latest 'transaction', where the customer judges the degree of consistency between expected service quality and the actual service delivered that is delivered $(15,16,17)$. Research suggests that satisfaction is an antecedent of service quality and in the literature it is often used as a proxy to measure service quality (18).

Satisfaction is monitored via Customer Satisfaction Surveys, typically in a 6 month or annual cycle $(19,20)$, where several indicators describing the service are monitored. Typically, respondents are asked to rate their satisfaction with service indicators, which can be used to monitor the quality of service over time. This provides useful information for transport managers and policy makers to allocate their recourses towards underperforming aspects of the service. However, several papers have demonstrated that not all service aspects are equally important in the evaluation of service quality by railway passengers. These studies look into the determinants of satisfaction by looking at the correlation of service aspect ratings with overall satisfaction using for instance factor analysis, while other studies try to comprehend implicit, latent drivers of satisfaction. Results from the literature generally suggest that crowdedness and reliability and to a lesser extent speed, vehicle cleanliness and frequency are the most important factors impacting passenger satisfaction in railway transport $(21,22,23,24)$. Comfort and information are also found to be relatively important (24), whereas other factors are found to be less important, such as personnel competence and safety (24).

Other studies try to explain service quality by looking at passenger heterogeneity. It is found that high and low frequency users of a transit system evaluate service quality differently, where low frequency users tend to be more positive $(24,25,26)$. Also, older respondents tend to be more positive about the quality of service $(23,25,27)$, as well as respondents with a good self reported health tend to report higher satisfaction ratings as well (27). Further studies examine the role of the railway station quality, which is defined through accessibility/connectivity by car and public transport. A few papers indicate that the accessibility of a railway station is an important factor in satisfaction with the train journey as well as the demand for the railway system (22, 28, 29). Their explanation is that a rail journey should be seen as a chain of journeys, where the passenger uses different modes to get from A to B. Other studies look into the retail value and station atmosphere and found that shopping, infotainment, music and lighting positively affect the waiting experience at stations $(30,31)$

To summarise, the rail satisfaction literature mostly focuses on the determinants of satisfaction. However, little research appears to have been done on the influence on service quality by the type of train service or type of station that the respondent used. This paper aims to fill this gap by using information on origin stations from respondents and the type of train service they used, whilst taking account of a range of relevant trip and socio-demographic factors. Trip factors that are considered are trip characteristics such as whether the respondent changed trains or incurred a delay. To our knowledge, these factors have not been evaluated using satisfaction data either. Further, personal characteristics and trip characteristics, such as trip purpose, age and gender are included in the model. This paper uses satisfaction data as a proxy for service quality, whereby the data is analysed using a partially constrained proportional odds model. The results can be used by TOCs and policy makers as a quantification of the impact of train and station factors, passenger segments and service disruptions in the evaluation of service quality.

\section{CONTEXTUAL INFORMATION AND DATA COLLECTION}

The data for this paper is extracted from the $32^{\text {nd }}$ wave of the National Rail Passenger Survey 
(NRPS), which was held in the spring of 2015 by Transport Focus (19). The sample used in this paper consists of around 30,000 observations on passenger satisfaction with the railway service across the network in the UK (excluding Northern Ireland). The surveys were distributed for each TOC, on stations that were selected using a probability proportionate to size using the estimated number of passengers departing from stations. A detailed explanation of the sampling process is provided at the Transport Focus website (19).

The returned surveys provide self-reported data on specific aspects of the train journey, personal characteristics, type of train service, as well as satisfaction ratings for specific aspects of the train service and overall satisfaction with the train journey.

Variables that are considered in this study can be grouped into four categories: train types, station types, personal characteristics and journey characteristics. Table 1 depicts the summary statistics for each variable that is considered in this paper.

\section{Passenger satisfaction}

The NRPS asks passengers to rate their satisfaction with the trip using the following question: "Taking into account just (station name) station where you boarded the train and the actual train travelled on after being given this questionnaire, how satisfied were you with your journey today?"

Table 1 depicts that the majority of the passengers (i.e. around 80\%) rate their satisfaction with their journey as fairly satisfied or very satisfied. Around $10 \%$ rate their journey as neither satisfied nor dissatisfied and the remaining $10 \%$ rate their journey as fairly dissatisfied or very dissatisfied. This indicates that most passengers perceive their journey as being of a reasonable quality.

\section{Train types}

The train type variables capture the type of train service that the respondent was travelling on. The UK has a variety of different train service types. The train service types are classified as being commuter rail, rural rail, inter-urban, long distance, high speed and open access rail. Each type of rail services has its own typical rolling stock and amenities to offer to their passengers.Commuter rail consists of mass rail transport serving large cities; with rolling stock accommodated to transfer as much passengers as possible from A to B and running at high frequencies. Rural rail consists of small scale railway operations in rural areas, often using small rolling stock and running at low frequencies of typically 1 train per hour. Inter urban trains are services between cities, offering longer distance commuting services between large conurbations, typically with a frequency of 2 trains per hour. Long distance trains offer services across the country, mostly with a frequency of 2 trains per hour. They offer on board catering and often higher speeds compared to inter urban rail. High speed trains offer similar amenites as long distance trains; however they run at higher speeds, up to $200 \mathrm{~km} / \mathrm{hr}$ and on High Speed 1 even faster, mostly with a frequency of 2 trains per hour. Finally, open access operators are included as a train type. These are train services that compete with franchise holders on specific lines, typically as long distance services to cities that are not very well connected by an incumbent franchise holder. Train services towards Heathrow airport are also operated by an open access operator. As Table 1 shows, around 53\% of the respondents travelled on commuter rail, respondents on rural and long distance each have around $8 \%$ of the respondents, inter urban rail has $12 \%$ and finally high speed has $11 \%$ of the respondents.

\section{Station types}

Respondents were asked to fill in their origin and destination station in the survey. In the data the origin and destination stations are coded according to the UK railway station categories set out by 
the Department for Transport. They are graded in categories A to F (32). Category A consists of so-called national hub major stations, which provide a gateway to the rail network from a large area, and acts as a significant interchange hub. Category B stations are large regional hub stations. They provide a gateway to the rail network from a large area and are often served by more than one TOC with a mix of service types. For some routes a category B station may be a terminus. Category $\mathrm{C}$ stations are important feeders on a busy trunk route, or a subsidiary hub. They are often served by more than one TOC and regular long-distance service. Category D stations are medium sized staffed stations with train services that connect with as an inter-urban service, or high-volume inner suburban services. Category E stations are small sized staffed station with only one member of staff, or else are only staffed for a part of the day. Category F stations are the smallest stations on the network and are unstaffed. In terms of accessibility, stations in the higher categories have very good public transport connectivity to the station catchment area, whereas lower category stations often have a lower quality of public transport connectivity towards the catchment area. In terms of amenities at the station, category A stations offers flagship facilities, toilets, customer service and high quality retail to its passengers, category B and C offer retail facilities and toilets as well, Category A to E are considered to have car parking and so on (32). Category $\mathrm{F}$ offers the most basic amenities to passengers. Including the station types should capture the effect of the access station on perceived service quality. Because passengers spend most of their waiting time in the access station, the destination station and interchange stations are not considered here.

\section{Personal characteristics}

The survey captures information on personal characteristics such as gender, age and trip purpose. These variables are included to control as much as possible for heterogeneity between individuals and segments. As every individual has its own preferences and needs, it could be that they evaluate their satisfaction with the railway service differently from other individuals.

\section{Trip characteristics}

Lastly, trip characteristics extracted from the survey about the respondents are included to control for the time of day, duration of trip, access mode to the station and whether the respondent incurred delays on his/her trip.

\section{STATISTICAL MODELS}

This paper uses satisfaction data which is coded on a five point scale from the lowest to the highest level (i.e. 1=very dissatisfied, 2= fairly dissatisfied, 3= neither satisfied nor dissatisfied, 4 = fairly satisfied, $5=$ very satisfied). As the dependent satisfaction variable has an ordinal structure, ordered logit models were deemed the most appropriate to use according to Williams (33). The dependent variable $y$ captures the ordinal response and represents an underlying latent variable $y_{i}^{*}$, which indicates the 'true' satisfaction with the railway service of respondent $i$. The model foundation with the latent $y_{i}^{*}$ is a regression model in the following form:

$y_{i}^{*}=\beta^{\prime} X_{i}+\varepsilon_{i}$

Where $X_{i}$ contains the corresponding values of respondent $i$ on the explanatory variables that describe station, train, personal and trip characteristics, $\beta^{\prime}$ represents the regression coefficients and $\varepsilon_{i}$ a random error term. The transformation of the latent $y_{i}^{*}$ into $y_{i}$, where $y_{i}$ takes each of the observable values i.e. $1, \ldots, m$ as follows (33): 


$$
\begin{gathered}
P\left(y_{i}=1\right)=f\left(-X_{i} \beta_{1}\right) \\
P\left(y_{i}=j\right)=f\left(-X_{i} \beta_{j}\right)-f\left(-X_{i} \beta_{j-1}\right) \\
P\left(y_{i}=m\right)=f\left(-X_{i} \beta_{m-1}\right)
\end{gathered} \quad \mathrm{j}=2, \ldots, \mathrm{m}-1 \ldots \ldots
$$

For the ordinal outcome the ordered logit model with $m$ outcome categories can be written as follows (34) :

$P\left(Y_{i}>j=\frac{\exp \left(X_{i} \beta_{j}-\alpha_{j}\right)}{1+\left[\exp \left(X_{i} \beta_{j}-\alpha_{j}\right)\right]}, \mathrm{j}=1,2, \ldots, \mathrm{m}-1\right.$

The parameters $\beta_{j}$ and the cut points $\propto_{j}$ are estimated using the maximum likelihood estimation method (33). The ordered logit model uses logistic distributions; hence the coefficients can be interpreted as logits. A requirement for the ordered logit model is that each $\beta$ should be the same for each level of satisfaction $j$, an assumption that is often referred to as the proportional odds assumption (33). However it may be the case that some $\beta^{\prime} s$ differ across different levels of $j$ while others do not. The Brant test can be used to test the null hypothesis that the coefficients in an ordered logit model meet the proportional odds assumption. The Brant test is a Wald test and it is based on the values of the coefficients and their variances. The test is performed for all the coefficients and for each single coefficient (34). If the null hypothesis is rejected, the proportional odds assumption is too restrictive, and relaxing the assumption for $\beta^{\prime} s$ where the assumption is violated poses a better model $(33,35)$. The partially constraints proportional odds model can be written as follows:

$P\left(Y_{i}>j\right)=\frac{\exp \left(X_{1} \beta_{1}+X_{2 i} \beta_{2 j}-\alpha_{j}\right)}{1+\left[\exp \left(X_{1} \beta_{1}+X_{2 i} \beta_{2 j}-\alpha_{j}\right)\right]} ; \quad \mathrm{j}=1,2, \ldots, \mathrm{M}-1$

The explanatory variables captured by $X_{1}$ are equal across different values of $j$ and variables captured by $X_{2}$ are allowed to vary across values of $j$. The model is fitted by the user written gologit2 command in Stata (35) and the model fit can be assessed by the McFadden pseudo $\mathrm{R}^{2}$ (35). The resulting coefficients are on the log odds scale; therefore marginal values are considered for interpretation to depict the probability of $X$ occurring in a certain level of $j$. Marginal effects can be obtained as follows, as is also used in the study by Kaplan et al. (36):

$\frac{\partial y_{i}}{\partial X_{i j k}}=\frac{P\left(y_{i}>j\left[\text { if } X_{i j k}=1\right]\right)-P\left(y_{i}>j\left[\text { if } X_{i j k}=0\right]\right)}{P\left(y_{i}>j\left[i f X_{i j k}=0\right]\right)}$

Where $X_{i j k}$ represents the $k$-th explanatory variable associated with response $j$ for respondent $i$.

\section{RESULTS}

The results of the model are displayed in Table 2. A Brant test was performed to establish the need of generalised ordered logit instead of ordered logit (34). The test indicated that most variables meet the proportional odds assumption; however some of the passenger characteristics and trip characteristics variables violate this assumption. Consequently, the partially constraint proportional odds model is preferred. The columns show the log odds of category 1 (very dissatisfied) versus all other categories, category 1 and 2 (very dissatisfied \& dissatisfied) versus all other categories and so on, until all categories versus category 5 (very satisfied). The McFadden pseudo $R^{2}$ is 0.092 . The value of the pseudo $R^{2}$ is low but not unusual when compared to other 
studies using satisfaction data on respondent's level, such as the study by Peiró on life satisfaction and socio economic conditions and Hensher on satisfaction in bus services $(37,38)$.

The following sections describe the results for type of train service, type of station and personal and trip characteristics, using equation 5 to estimate the marginal effects.

\section{Type of train service}

The results indicate that all train services except for rural rail are likely to be perceived better than commuter rail. The difference in the probability of being very satisfied is especially striking when commuter rail is compared with open access operators. Equation 5 can be used to estimate the marginal effects, which for instance goes as follows (equation 6) when considering open access operators:

$\frac{\partial \operatorname{Pr}(\mathrm{y}=\text { very satisfied })}{\partial(\text { Open access operator })}=0.13$

This indicates that open access trains are 13\% more likely to rate the service as very good compared to passengers on commuter rail. Further analys shows that respondents on high speed rail are $9 \%$ more likely to rate the service as very good compared to commuter rail. Also long distance trains are significantly more likely to be rated as very good compared to commuter rail.

\section{Type of station}

The results on station types do not show very strong results, however passengers that accessed the train on stations in category $\mathrm{E}$ and $\mathrm{F}$ are (3.5\% to 5\% respectively, using equation 5) more likely to rate the train service as very good compared to passengers that accessed the train in category A stations. Interestingly, the results indicate that the station type does not have a strong impact on overall satisfaction. This could indicate that the access station is not considered as being an important part of the train service by respondents.

\section{Personal characteristiscs}

Results on passenger characteristics indicate that females, infrequent passengers and older passengers are more likely to rate the service as very good. The effects are particularly strong in the age category 65+ where passengers are more likely (20\% respectively, using equation 5) to rate their experience with the train service as very good relatively to respondents in the age category 16-24. This is an interesting result as young passengers can travel with $30 \%$ discount using a Railcard. Overall however, the results are in line with several other studies that show that females, infrequent passengers and older passengers are more satisfied with public transport services (23, 24).

\section{Trip characteristics}

Results on trip characteristics show some interesting outcomes. The trip purpose of passengers show that passengers with business and leisure trip purposes are more likely to rate the train service as very good, compared to commuters. Mouwen obtains similar results for Dutch bus and regional rail (23).

Further findings indicate that passengers with long journey times are less likely to rate the train service as very good. Trip characteristics related to the time of travel show that travellers during the peak are less likely to rate the train service as very good than off peak users (4.5\% respectively, using equation 5), whilst users during the weekend are likely to be more satisfied than those who use services during the week (8\% respectively, using equation 5). Respondents facing disturbing 
behavior on the train are less likely to rate the service as very good (10\% respectively, using equation 5). The results on access into station show no significant or strong results, indicating that the access into the station does not impact on perceived quality. This contradicts findings in other papers as the earlier mentioned $(21,28)$ which did find an impact of the access mode in perceived quality.

The strongest result of the analysis is that passengers that incurred a delay on route are $24 \%$ less likely to rate the train service as very good and 9\% more likely to rate the service as fairly poor and 5\% more likely to rate the service as very poor (using equation 5). As passengers themselves indicate whether they incurred a delay, it can be assumed that the disruption was noticed by the passenger and therefore their critical level of reliability was not met. The importance of punctuality is also stressed in other publications using satisfaction data $(22,23,24)$; however none of these used information on whether the respondent actually incurred a delay, but looked at the correlation of perceived punctuality with perceived service quality.

\section{Policy implications}

The results on train and types indicate that all the train services are more likely to be rated as very good compared to commuter rail, which indicates that commuter rail in the UK faces more difficulties to meet expectations. This might be explained by factors such as crowdedness, or customers in urban areas being more critical in their evaluation of service quality. It is important to further investigate this finding, as in light of issues such as congestion and pollution in urban areas, there is a societal need for commuter rail to be competitive with private cars. The results on station types indicate that relative to category A stations, the station category does not significantly impact on perceived service quality. This could indicate that stations do not play a large role in the evaluation of service quality, which is an important finding for policy makers.

Next, an important result is that investments aimed at minimising the impacts of service disruption should lead to more satisfied passengers. If a respondent reports a delay in the survey, the respondent is $25 \%$ less likely to rate the service as very good and $9 \%$ more likely to rate the service as fairly poor and 5\% more likely to rate the service as very poor. Above that, the NRPS report in spring 2015 indicates that only 34\% of the respondents that incurred a delay are satisfied with how the TOC dealt with the delay (8). Policies aimed at minimising the discomfort when delays occur could therefore also be effective and are perhaps preferable in light of the large costs that may go hand in hand with reliability improvements.

Lastly, results on passenger segmentation show that policies aimed at improving the experience of young travellers, males and commuters could lead to more satisfied passengers. Especially improving the experience of young passengers in the age 16-24 may yield beneficial results as they are $20 \%$ less likely to rate the train service as very good compared to the oldest category. This finding may indicate that there are expectation differences amongst age groups. This needs further research, and could have implications for TOCs with a higher share of younger passengers.

\section{DISCUSSION}

This study has some limitations. The most important limitation is that the study quantifies the impact of passenger segments and other factors impacting service quality, but does not explain them. For instance, the results indicate that females are more likely to rate the service as very good, however it is unknown why this is the case. This makes it difficult to quantify benefits of policies aimed at improving the perceived quality for these segments and factors without knowing why these factors impact on satisfaction. Therefore, further research is needed in this direction.

A further limitation is that factors impacting on passenger satisfaction are difficult to 
capture, which is reflected in the low pseudo $\mathrm{r}$ squared value. Aside from the factors that are included in the model, it is likely that there are more factors impacting on satisfaction, such as weather, behavior of fellow passengers, income level e.g. Every respondent has its own expectations, experiences and preferences' regarding the railway service and it is very difficult to capture this heterogeneity. Therefore policies aimed at segments will yield results, but will also leave passengers in those segments not benefiting from these particular measures.

Another limitation lies in the composition of the respondents. Non users are not included and therefore their opinion about rail transport is not observed. The perception of non users is very relevant, as one of the aims of improving service quality is to attract new passengers. A possible limitation also lies in potential expectation differences amongst groups of travelers, which may affect outcomes on station types and train types. Passengers accessing the railway on a small station might have different expectations regarding the railway compared to passengers accessing the railway on larger stations. Resulting outcomes could therefore also suggest a difference in expectations regarding the services the railway has to offer.

The strongest results are found to be the impact of delays on satisfaction. The limitation of this finding is that there is no distinction between predictable or unpredictable delays. In commuter rail it is likely that during rush hour trains suffer from minor delays, which is something travellers can adapt to. However unpredictable delays, such as infrastructural failure, may have a very different impact on the attitudes and satisfaction of travellers, as for instance the study of König (39) indicates. In the latter case, it could be that the handling of the particular delay becomes very important, and this could therefore prove to be an interesting case for further research. Further, there are possible differences among segments in the impact of delays on perceived service quality that are not researched.

\section{CONCLUSIONS}

Service quality from a passenger's point of view should form a key component in the evaluation of any transport system. Passengers are the users of the system, and hence they are best placed to judge whether the service meets their expectations $(10,11)$. Service quality not only matters to passengers, but also to operators and politicians, because passenger perceptions of service quality could directly translate towards the success of a transit system in terms of demand and revenue as passengers could switch to alternative modes of transport if the service does not meet expectations $(1,2,3)$. Next, service quality is of importance because it is used to monitor and benchmark performances. Service quality measures are increasingly used in franchise contracts where payments to TOCs relate to the satisfaction level of its customers. Further, research has shown that poor satisfaction leads to a long term reputation damage (6), which may have long term impacts in terms of patronage levels and the chance for the TOC involved to win future franchises. For all these reasons it is very important to understand how passengers evaluate service quality, and which factors impact their perception. Therefore, this paper looks into the impact of station types and train types as well as personal and trip characteristics on service quality, where satisfaction data is used as a proxy to measure service quality. The data is obtained by using the NRPS, a passenger survey which is held biannually by Transport Focus for UK rail transport (19).

The most relevant findings are that commuter rail is less likely to be rated as very good relative to other type of train services. Further, station types and the access mode to the railway station do not significantly impact on perceived service quality. These findings provide directions for policy makers and TOCs in their efforts to improve service quality. Perhaps the most interesting finding of this paper is the large impact of delays on the level of passenger satisfaction. Passengers 
themselves have indicated if they incurred a delay on route in the survey. Thus, the result demonstrates that if their own minimum standard of reliability was not met, they become far more likely to be dissatisfied. Policies aimed at improving the reliability and improving the handling with delays should therefore lead to a higher service quality, where perhaps the latter approach is preferred in light of the large investment costs that go hand in hand with improving reliability.

Further results show the importance of policies aimed at passenger segments. Especially striking is the result on age, where it is shown that people in the oldest age category are $20 \%$ more likely to rate the service as very good compared to the youngest age category, which may be explained by differences in expectations among age categories. The trip purpose also matters as commuters are less likely to be satisfied compared to respondents on a business or leisure trip. Products and investments aimed at improving the experience amongst different segments could yield more satisfied passengers.

The contribution of this paper is that it highlights the impact on service quality of train and station types. Also the impact of delays on service quality is highlighted as well as the impact of several other trip characteristics such as the impact of changing trains and the journey time as well as the role of different passenger segments. These results should be used in combination with research on why these of differences in service quality evalution occur. This will be very useful for policy makers and TOCs and provide important insights for investment decisions aimed at improving service quality.

\section{ACKNOWLEDGEMENTS}

The authors acknowledge Transport Focus for delivering the NRPS data. This research was funded by a grant of the UK Engineering and Physical Sciences Research Council (ESPRC).

\section{REFERENCES}

1. Richard, M.D. \& Allaway, A.W., 1993. Service Quality Attributes and Choice Behavior. Journal of Services Marketing, 7, pp.59-68.

2. Anderson, S., Pearo, L.K. \& Widener, S.K., 2008. Drivers of Service Satisfaction: Linking Customer Satisfaction to the Service Concept and Customer Characteristics. Journal of Service Research, 10(4), pp.365-381.

3. de Oña, J. et al., 2016. Transit passengers' behavioural intentions: the influence of service quality and customer satisfaction. Transportmetrica A: Transport Science, 9935(April), pp.1-29.

4. Chou, P., Lu, C. \& Chang, Y., 2014. Transportmetrica A : Transport Science Effects of service quality and customer satisfaction on customer loyalty in high-speed rail services in Taiwan. , 9935(September 2016)

5. TSGN franchise agreement. Department for Transport, UK Government, UK Government. www.gov.uk/government/uploads/system/uploads/attachment_data/file/525766/tsg n-franchise-agreement.pdf. Accessed June 25, 2016.

6. Gijsenberg, M.J., Van Heerde, H.J. \& Verhoef, P.C., 2015. Losses Loom Longer Than Gains: Modelling the Impact of Service Crises on Perceived Service Quality over Time. Journal of Marketing Research, 52(5), pp.642-656.

7. Bowman, A. et al., 2013. The Great Train Robbery: Rail Privatisation and After. CRESC: Public Interest Report, pp.1-167.

8. Transport Focus 2015 Main Report. Transport Focus. www.transportfocus.org.uk/research-publications/publications/national-rail-passen 
ger-survey-nrps-spring-2015-main-report. Accessed June 5, 2016

9. Office of rail and road. Passenger rail usage 2015-16 Q4. www.orr.gov.uk/_data/assets/pdf_file/0015/22056/passenger-rail-usage-2015-16q4.pdf. Accessed July 31, 2016.

10. Berry, L.L., Zeithaml, V.A., Parasuraman, A., 1990. Five imperatives for improving service quality. Sloan Management Review Summer, 9-38.

11. Eboli, L. \& Mazzulla, G., 2011. A methodology for evaluating transit service quality based on subjective and objective measures from the passenger's point of view. Transport Policy, 18(1), pp.172-181.

12. Hensher, D.A., 2013. The Relationship Between Bus Contract Costs, User Perceived Service Quality and Performance Assessment. International Journal of Sustainable Transportation, 8(1), pp.5-27.

13. European Committee For Standardization, 2002. Transport - Logistics and Services - Public Passenger Transport - Service Quality Definition Target and Measurement. European Standard EN 13816. (CEN).

14. Hensher, D.A., Stopher, P. \& Bullock, P., 2003. Service quality - developing a service quality index in the provision of commercial bus contracts. Transportation Research Part A: Policy and Practice, 37(6), pp.499-517.

15. Cronin, J., Taylor, S.A., 1993. Measuring Service Quality - A Reexamination And Extension. Journal of Marketing, 57(3), pp.55-68.

16. Parasuraman, A., V. A. Zeithaml, and L. L. Berry. 1985. "A Conceptual Model of Service Quality and its Implications for Future Research.” The Journal of Marketing 49 (4): 41-50.

17. Bitner, M.J., 1990. Evaluating service encounters: the effect of physical surroundings and employee responses. Journal of Marketing 54, 69-82.

18. Becker, J.U. \& Albers, S., 2015. The limits of analyzing service quality data in public transport. Transportation, pp.823-842.

19. Transport Focus Technical Guide Spring 2015. Transport Focus. www.transportfocus.org.uk/research-publications/publications/nrps-technical-guid e-spring-2015.Accessed 14 June, 2016.

20. OV klantbarometer. Opzet en systematiek van het onderzoek 2015. www.ovklantbarometer.nlPortals/0/K036-30_Onderzoeksopzet\%20website.pdf. Accessed November 2, 2016.

21. Brons, M., Givoni, M. \& Rietveld, P., 2009. Access to railway stations and its potential in increasing rail use. Transportation Research Part A: Policy and Practice, 43(2), pp.136-149.

22. Mouwen, A. \& Rietveld, P., 2013. Does competitive tendering improve customer satisfaction with public transport? A case study for the Netherlands. Transportation Research Part A: Policy and Practice, 51, pp.29-45.

23. Mouwen, A., 2015. Drivers of customer satisfaction with public transport services. Transportation Research Part A: Policy and Practice, 78, pp.1-20.

24. Eboli, L. \& Mazzulla, G., 2012. Structural Equation Modelling for Analysing Passengers’ Perceptions about Railway Services. Procedia - Social and Behavioral Sciences, 54, pp.96-106.

25. Andreassen, W. "(Dis)satisfaction with public services: the case of public transportation.” Journal of Service Marketing, 9 (5), 1995: 30-41.

26. Tyrinopoulos, Y. \& Antoniou, C., 2008. Public transit user satisfaction: Variability 
and policy implications. Transport Policy, 15(4), pp.260-272.

27. Ye, R. \& Titheridge, H., 2016. Satisfaction with the commute: The role of travel mode choice, built environment and attitudes. Transportation Research Part D: Transport and Environment

28. Gorter, C., Nijkamp, P. \& Vork, R., 2000. Analysis of travellers' satisfaction with transport chains. Transportation Planning and Technology, 23(April), pp.237-258.

29. Debrezion, G., Pels, E. \& Rietveld, P., 2009. Modelling the joint access mode and railway station choice. Transportation Research Part E: Logistics and Transportation Review, 45(1), pp.270-283.

30. Mark van Hagen, 2015. Effect of Station Improvement Measures on Customer Satisfaction. Journal of Traffic and Transportation Engineering, 3(1), pp.7-18.

31. Geetika, S.N., 2010. Determinants of Customer Satisfaction on Service Quality : A Study of Railway Platforms in India. Journal of Public Transportation, 13(Gronroos 1984), pp.97-113.

32. Better rail stations. Independent review for Department for Transport, UK government.

www.dft.gov.uk/pgr/rail/passenger/stations/betterrailstations/pdf/report.pdf.

Accessed July 4, 2016

33. Williams, R., 2006. Generalized ordered logit/partial proportional odds models for ordinal dependent variables. Stata Journal, 6(1), pp.58-82.

34. Brant, R. (1990). Assessing Proportionality in the Proportional Odds Model for Ordinal Logistic Regression. Biometrics, 46(4), 1171-1178.

35. Williams, R., 2016. Understanding and interpreting generalized ordered logit models. The Journal of Mathematical Sociology, 5874(April), pp.1-14.

36. Kaplan, S. \& Prato, C.G., 2012. Risk factors associated with bus accident severity in the United States: A generalized ordered logit model. Journal of Safety Research, 43(3), pp.171-180.

37. Hensher, D.A., Mulley, C. \& Yahya, N., 2010. Passenger experience with quality-enhanced bus service: The tyne and wear "superoute" services. Transportation, 37(2), pp.239-256.

38. Peiró, A., 2006. Happiness, satisfaction and socio-economic conditions: Some international evidence. Journal of Socio-Economics, 35(2), pp.348-365.

39. König, A. \& Axhausen, K.W., 2002. The reliability of the Transportation System and its influence on the Choice Behaviour. Proceedings of the 2nd Swiss Transportation Research Conference.

\section{LIST OF TABLES}

TABLE 1 Summary statistics of the variables included in the model

TABLE 2 Estimation results of the partially constrained ordered logit model 
TABLE 1 Summary statistics of the variables included in the model

\begin{tabular}{|c|c|c|c|}
\hline \multicolumn{2}{|l|}{ Variable } & Frequency & Percentage \\
\hline \multirow[t]{5}{*}{ Overall satisfaction with trip: } & Very dissatisfied & 611 & 2 \\
\hline & Fairly dissatisfied & 1380 & 4.6 \\
\hline & Neither satisfied nor dissatisfied & 3056 & 10.0 \\
\hline & Fairly satisfied & 14430 & 47.3 \\
\hline & Very satisfied & 10825 & 35.7 \\
\hline \multirow[t]{6}{*}{ Type of train service: } & Commuter train & 16688 & 53.6 \\
\hline & Rural train & 2425 & 7.8 \\
\hline & Inter-urban train & 4002 & 12.8 \\
\hline & Long distance train & 2475 & 7.9 \\
\hline & High speed train & 3185 & 10.2 \\
\hline & Open access train & 2385 & 7.7 \\
\hline \multirow[t]{6}{*}{ Type of station: } & Station category A & 12168 & 40 \\
\hline & Station category B & 6277 & 20.6 \\
\hline & Station category C & 6098 & 20.1 \\
\hline & Station category D & 2794 & 9.2 \\
\hline & Station category E & 2006 & 6.6 \\
\hline & Station category F & 1067 & 3.5 \\
\hline \multirow[t]{10}{*}{ Personal characteristics: } & Respondent is male & 13752 & 45.3 \\
\hline & Respondent is female & 16592 & 54.7 \\
\hline & $\begin{array}{l}\text { Respondent uses train more than } \\
\text { one time per week }\end{array}$ & 13889 & 44.6 \\
\hline & $\begin{array}{l}\text { Respondent uses train less than } \\
\text { once or once per week }\end{array}$ & 17271 & 55.4 \\
\hline & Respondent $16-24$ years old & 3458 & 11.3 \\
\hline & Respondent 25-34 years old & 4181 & 13.7 \\
\hline & Respondent 35-44 years old & 5347 & 17.5 \\
\hline & Respondent 45-54 years old & 6940 & 22.7 \\
\hline & Respondent 55-64 years old & 6206 & 20.3 \\
\hline & Respondent $>65+$ years old & 4395 & 14.4 \\
\hline \multirow[t]{23}{*}{ Trip characteristics: } & Respondent travelled second class & 28835 & 95.9 \\
\hline & Respondent travelled first class & 1232 & 4 \\
\hline & Disturbing behavior in train & 2391 & 8 \\
\hline & Commuter trip & 12812 & 41.1 \\
\hline & Business trip & 4928 & 15.8 \\
\hline & Leisure trip & 13420 & 43.1 \\
\hline & Journey time $<30$ minutes & 11432 & 38.7 \\
\hline & Journey time 30-60 minutes & 9577 & 32.4 \\
\hline & Journey time 60-120 minutes & 5135 & 17.4 \\
\hline & Journey time $120-180$ minutes & 2252 & 7.6 \\
\hline & Journey time $>180$ minutes & 1178 & 4 \\
\hline & Off peak travel & 20628 & 66.2 \\
\hline & Peak travel & 10532 & 33.8 \\
\hline & Weekday trip & 26352 & 84.6 \\
\hline & Weekend trip & 4808 & 15.4 \\
\hline & Respondent did not incur a delay & 25253 & 81 \\
\hline & Respondent incurred a delay & 5907 & 19 \\
\hline & No changing trains during trip & 26104 & 83.8 \\
\hline & Changing trains during trip & 5056 & 16.2 \\
\hline & Respondent walked to station & 10704 & 34.4 \\
\hline & Respondent used car to station & 7492 & 24 \\
\hline & Respondent used PT to station & 11648 & 37.4 \\
\hline & $\begin{array}{l}\text { Respondent used boat or plane to } \\
\text { station }\end{array}$ & 1316 & 4.2 \\
\hline
\end{tabular}


TABLE 2 Estimation results of the partially constraints proportional odds model

\begin{tabular}{|c|c|c|c|c|c|}
\hline \multicolumn{2}{|l|}{ Independent variables } & $\begin{array}{l}1 \text { versus } \\
2,3,4,5_{a}\end{array}$ & $\begin{array}{l}1,2 \text { versus } \\
3,4,5_{a}\end{array}$ & $\begin{array}{l}1,2,3 \text { versus } \\
4,5_{a}\end{array}$ & $\begin{array}{l}1,2,3,4 \\
\text { versus } 5_{a}\end{array}$ \\
\hline \multirow[t]{6}{*}{ Type of train service: } & Commuter train (base) & na & na & na & na \\
\hline & Rural train $^{+}$ & $-0.55^{* * *}$ & $-0.24^{* * *}$ & $-0.15^{* *}$ & -0.078 \\
\hline & Inter-urban train & $0.15^{* * *}$ & $0.15^{* * *}$ & $0.15^{* * *}$ & $0.15^{* * *}$ \\
\hline & Long distance train & $0.18^{* * *}$ & $0.18^{* * *}$ & $0.18^{* * *}$ & $0.18^{* * *}$ \\
\hline & High speed train & $0.37^{* * *}$ & $0.37^{\text {*** }}$ & $0.37^{* * *}$ & $0.37^{* * *}$ \\
\hline & Open access train $^{+}$ & $1.04^{* * *}$ & $1.04^{* * *}$ & $1.04^{* * *}$ & $1.04^{* * *}$ \\
\hline \multirow[t]{6}{*}{ Type of station: } & Station category A (base) & na & na & na & na \\
\hline & Station category B & $0.059^{*}$ & $0.059^{*}$ & $0.059^{*}$ & $0.059^{*}$ \\
\hline & Station category C & 0.021 & 0.021 & 0.021 & 0.021 \\
\hline & Station category D & $0.084^{*}$ & $0.084^{*}$ & $0.084^{*}$ & $0.084^{*}$ \\
\hline & Station category E & $0.16^{* * *}$ & $0.16^{\text {*** }}$ & $0.16^{* * *}$ & $0.16^{* * *}$ \\
\hline & ${\text { Station category } \mathrm{F}^{+}}^{+}$ & $0.60^{* *}$ & 0.20 & -0.041 & $0.20^{* * *}$ \\
\hline \multirow[t]{10}{*}{ Personal characteristics: } & Respondent is male (base) & na & na & na & na \\
\hline & Respondent is female & $0.26^{* * *}$ & $0.16^{* * *}$ & $0.30^{* * *}$ & $0.30^{* * *}$ \\
\hline & $\begin{array}{l}\text { Respondent uses train more } \\
\text { than once per week (base) }\end{array}$ & na & na & na & na \\
\hline & $\begin{array}{l}\text { Respondent uses train less } \\
\text { than once or once per week }\end{array}$ & $0.61^{* * *}$ & $0.44^{* * *}$ & $0.43^{* * *}$ & $0.13^{* * *}$ \\
\hline & $\begin{array}{l}\text { Respondent 16-24 years old } \\
\text { (base) }\end{array}$ & na & na & na & na \\
\hline & Respondent $25-34$ years old & $-0.19^{* * *}$ & $-0.19^{* * *}$ & $-0.19^{* * *}$ & $-0.19^{* * *}$ \\
\hline & Respondent $35-44$ years old $^{+}$ & -0.21 & $-0.33^{* * *}$ & $-0.19^{* * *}$ & -0.061 \\
\hline & Respondent $45-54$ years old $^{+}$ & $-0.22^{*}$ & $-0.28^{* * *}$ & $-0.13^{* * *}$ & $0.11^{* *}$ \\
\hline & Respondent 55-64 years old $^{+}$ & -0.18 & $-0.18^{* *}$ & 0.027 & $0.36^{* * *}$ \\
\hline & Respondent $>65$ years old ${ }^{+}$ & $0.34^{*}$ & 0.15 & $0.59^{* * *}$ & $0.85^{* * *}$ \\
\hline \multirow[t]{19}{*}{ Trip characteristics: } & $\begin{array}{l}\text { Respondent travelled second } \\
\text { class (base) }\end{array}$ & na & na & na & na \\
\hline & $\begin{array}{l}\text { Respondent travelled first } \\
\text { class }\end{array}$ & $0.13^{* *}$ & $0.13^{* *}$ & $0.13^{* *}$ & $0.13^{* *}$ \\
\hline & Disturbing behaviour in train & $-1.03^{* * *}$ & $-0.80 * * *$ & $-0.83 * * *$ & $-0.57 * * *$ \\
\hline & Commuter trip (base) & na & na & na & na \\
\hline & Business trip & $0.19^{* * *}$ & $0.19^{* * *}$ & $0.19^{* * *}$ & $0.19^{* * *}$ \\
\hline & Leisure trip $^{+}$ & 0.13 & $0.38^{* * *}$ & $0.43^{* * *}$ & $0.53^{* * *}$ \\
\hline & $\begin{array}{l}\text { Journey time }<30 \text { minutes } \\
\text { (base) }\end{array}$ & na & na & na & na \\
\hline & Journey time $30-60$ minutes & -0.045 & -0.045 & -0.045 & -0.045 \\
\hline & Journey time 60-120 minutes & $-0.18^{* * *}$ & $-0.18^{* * *}$ & $-0.18^{* * *}$ & $-0.18^{* * *}$ \\
\hline & $\begin{array}{l}\text { Journey time 120-180 } \\
\text { minutes }\end{array}$ & $-0.089^{* *}$ & $-0.089^{* *}$ & $-0.089^{* *}$ & $-0.089^{* *}$ \\
\hline & Journey time $>180$ minutes & $-0.17^{* * *}$ & $-0.17^{* * *}$ & $-0.17^{* * *}$ & $-0.17^{* * *}$ \\
\hline & Off peak travel (base) & na & na & na & na \\
\hline & $\begin{array}{l}\text { Peak travel }(07: 00-08: 59 \& \\
17: 00-18: 59)^{+}\end{array}$ & $-0.39^{* * *}$ & $-0.30^{* * *}$ & $-0.18^{* * *}$ & $-0.21^{* * *}$ \\
\hline & Weekday trip (base) & na & na & na & na \\
\hline & Weekend trip & $0.065^{*}$ & $0.065^{*}$ & $0.065^{*}$ & $0.065^{*}$ \\
\hline & $\begin{array}{l}\text { Respondent did not incur a } \\
\text { delay (base }\end{array}$ & na & na & na & na \\
\hline & Respondent incurred a delay $^{+}$ & $-2.13^{* * *}$ & $-1.90^{* * *}$ & $-1.50^{* * *}$ & $-1.32^{* * *}$ \\
\hline & $\begin{array}{l}\text { No changing trains during trip } \\
\text { (base) }\end{array}$ & na & na & na & na \\
\hline & Changing trains during trip & $-0.10^{* * *}$ & $-0.10^{* * *}$ & $-0.10^{* * *}$ & $-0.10^{* * *}$ \\
\hline
\end{tabular}




\begin{tabular}{|c|l|l|l|l|}
\hline Independent variables (continued) & $\begin{array}{l}1 \text { versus } \\
2,3,4,5_{a}\end{array}$ & $\begin{array}{l}1,2 \text { versus } \\
3,4,5_{a}\end{array}$ & $\begin{array}{l}1,2,3 \text { versus } \\
4,5_{a}\end{array}$ & $\begin{array}{l}1,2,3,4 \\
\text { versus } 5_{a}\end{array}$ \\
\hline $\begin{array}{l}\text { Respondent walked to station } \\
\text { (base) }\end{array}$ & na & na & na \\
\hline $\begin{array}{l}\text { Respondent arrived by car at } \\
\text { station }\end{array}$ & 0.046 & 0.046 & 0.046 & 0.046 \\
\hline $\begin{array}{l}\text { Respondent arrived by public } \\
\text { transport at station }\end{array}$ & -0.018 & -0.018 & -0.018 & -0.018 \\
\hline $\begin{array}{l}\text { Respondent arrived by plane } \\
\text { or boat at station }{ }^{+}\end{array}$ & $-0.88^{* * *}$ & $-0.29^{*}$ & -0.095 & -0.066 \\
\hline Statistics & & & & $1.55^{* * *}$ \\
\hline Constant & $4.73^{* * *}$ & $3.21^{* * *}$ & $-1.14^{* * *}$ \\
\hline Observations & 29541 & & & \\
\hline McFadden Pseudo $R^{2}$ & 0.092 & & & \\
\hline Log likelihood at convergence & -31457.8 & & \\
\hline
\end{tabular}

${ }^{*} p<0.1,{ }^{* *} p<0.05,{ }^{* * *} p<0.01$

a 1 = very dissatisfied, 2 = fairly dissatisfied, 3 = neither satisfied nor dissatisfied, $4=$ fairly satisfied, $5=$ very satisfied

${ }^{+}$Variables that violated the proportional odds assumption 